\title{
1 Impact of sleep fragmentation, heart failure, and their combination, on
}

\section{the gut microbiome}

4 Olfat Khannous-Lleiffe ${ }^{1,2}$, Jesse R. Willis ${ }^{1,2}$, Ester Saus ${ }^{1,2}$, Ignacio Cabrera-Aguilera ${ }^{3,4}$,

5 Isaac Almendros ${ }^{3,5,6}$, Ramon Farré ${ }^{3,5,6}$, David Gozal ${ }^{7}$, Nuria Farré ${ }^{8-10, *}$, and Toni

6 Gabaldón ${ }^{1,2,11, *}$

7 *Both authors share senior authorship and correspondence.

10 1) Barcelona Supercomputing Centre (BSC-CNS). Jordi Girona, 29. 08034. Barcelona, Spain.

11 2) Institute for Research in Biomedicine (IRB Barcelona), The Barcelona Institute of Science and

12 Technology, Baldiri Reixac, 10, 08028 Barcelona, Spain

13 3) Unitat de Biofísica i Bioenginyeria, Facultat de Medicina i Ciències de la Salut, Universitat de 14 Barcelona, Barcelona, Spain

15 4) Department of Human Movement Sciences, Faculty of Health Sciences, School of Kinesiology, 16 Universidad de Talca, Talca, Chile

17 5) CIBER de Enfermedades Respiratorias, Madrid, Spain

18 6) Institut d'Investigacions Biomèdiques August Pi i Sunyer, Barcelona, Spain

19 7) Department of Child Health and Child Health Research Institute, The University of Missouri

20 School of Medicine, Columbia, MO, United States

21 8) Heart Failure Unit, Department of Cardiology. Hospital del Mar (Parc de Salut Mar). Barcelona

22 9) Heart Diseases Biomedical Research Group, IMIM (Hospital del Mar Medical Research

23 Institute), Barcelona, Spain

24 10) Department of Medicine, Universitat Autònoma de Barcelona, Barcelona, Spain

25 11) Catalan Institution for Research and Advanced Studies (ICREA), Barcelona, Spain

31 Heart Failure Programme, Department of Cardiology 
bioRxiv preprint doi: https://doi.org/10.1101/2020.09.11.294447: this version posted September 15. 2020. The copvriaht holder for this preprint (which was not certified by peer review) is the author/funder, who has granted bioRxiv a license to display the preprint in perpetuity. It is made available under aCC-BY-NC 4.0 International license.

\section{Hospital del Mar}

33 Passeig Marítim, 25-29

3408003 Barcelona, Spain.

35 E-mail address: NFarreLopez@ parcdesalutmar.cat

36

37 *Dr. Toni Gabaldon, $\mathrm{PhD}$

38 Barcelona Supercomputing Centre (BSC-CNS)

39 Jordi Girona, 29

4008034 Barcelona, Spain

41 Email address: toni.gabaldon.ben@gmail.com

42

43

44 


\section{ABSTRACT}

46 Heart failure (HF) is a common condition associated with a high rate of

47 hospitalizations and adverse outcomes. HF is characterized by impairments of the cardiac

48 ventricular filling and/or ejection of blood capacity. Sleep fragmentation (SF) involves a

49 series of short sleep interruptions that lead to fatigue and contribute to cognitive

50 impairments and dementia. Both conditions are known to be associated with increased

51 inflammation and dysbiosis of the gut microbiota. In the present study, male mice were

52 distributed into four groups, and subjected for four weeks to either HF, SF, both HF and

$53 \mathrm{SF}$, or left unperturbed as controls. We used 16S metabarcoding to assess fecal microbiome

54 composition before and after the experiments. Evidence for distinct alterations in several

55 bacterial groups and an overall decrease in alpha diversity emerged in HF and SF treatment

56 groups. Combined HF and SF conditions, however, showed no synergism, and observed

57 changes were not always additive, suggesting that some of the individual effects of either

58 HF or SF cancel each other out when applied concomitantly.

\section{IMPORTANCE:}

60 The study demonstrates the potential of the gut microbiome as a source of molecular

61 markers for the diagnosis, prevention, and treatment of both heart failure and sleep

62 fragmentation conditions in isolation. Our results provide the first evidence of an

63 antagonistic effect of the presence of both conditions in the gut microbiome dysbiosis,

64 showing an attenuation of the alterations that are observed when considering them

65 separately. 
66 KEYWORDS: Metagenomics; Microbiome; Sleep fragmentation; Heart failure; Sleep

67 apnea.

\section{INTRODUCTION}

Heart failure (HF) is a prevalent disease associated with a poor, yet variable

71 prognosis whose causal mechanisms are not entirely understood (Camps-Vilaro et al.

72 2020). Comorbidities, such as sleep apnea, are frequent in patients with HF, and have been

73 associated with a worsened prognosis (Farre et al. 2017). The adverse outcomes associated

74 with the co-existence of $\mathrm{HF}$ and sleep apnea have been attributed, at least in part, to

75 excessive activation of the sympathetic autonomic nervous system (Cowie et al. 2017,

76 Javaheri et al. 2020), yet there is substantial variability underlying these relationships

77 suggesting that other upstream factors may be also involved. Among these factors, the gut

78 microbiome, a vast and complex polymicrobial community that coexists with the human

79 host and is extraordinarily adaptable to a variety of intrinsic or extrinsic changes, plays an

80 important role in the development of immunological phenotypes and in host metabolism

81 (Tremaroli et al. 2012), and could be implicated in the adverse outcomes of HF-sleep apnea

82 (Mashaqi et al. 2019).

83 Indeed, previous studies have shown evidence implicating the gut microbiome in

84 the physiopathology and prognosis of HF (Tang et al. 2017). HF is associated with reduced

85 microbiome diversity (Luedde et al. 2017) and a shift in the major bacterial phyla, resulting

86 in a lower Firmicutes/Bacteroidetes ratio (Mayerhofer et al. 2020), an increase in

87 Enterbacterales, Fusobacterium and Ruminococcus gnavus, but also in a decrease in 

et al 2017). Moreover, some intestinal microbial metabolites (e.g. trimethylamine-N-oxide

90 (TMAO) and its precursors) are present in higher amounts in patients with chronic HF, and

91 elevated levels of TMAO have been independently associated with an increased risk of

92 mortality in acute and chronic HF (Suzuki et al. 2016). Furthermore, patients with HF,

93 present high blood levels of endotoxins, lipopolysaccharides (LPS), and tumor necrosis

94 factor (TNF) (Genth-Zotz et al. 2002) and have increased thickness of the intestinal wall,

95 elevated intestinal permeability and intestinal ischemia (Sandek et al. 2007). All these

96 observations suggest a causal relationship between HF and gut dysbiosis and the edematous

97 intestinal wall, epithelial dysfunction, and the translocation of LPS and endotoxins through

98 the intestinal epithelial barrier promoting a mechanistic pathway that ultimately aggravates

$99 \mathrm{HF}$ and leads to accelerated cardiac decompensation.

100 Sleep apnea is a highly prevalent comorbidity in HF (Cowie et al. 2017), is

101 characterized by episodic hypoxia and intermittent arousals leading to sleep fragmentation

102 (SF). Like many other disorders, sleep apnea has recently been associated with gut

103 dysbiosis and systemic inflammation (Ko et al, 2019). SF, one of the hallmark components

104 of sleep apnea, has been less extensively examined than intermittent hypoxia (Moreno-

105 Indias et al. 2015; Tripathi et al. 2018), but studies to date have shown that it induces gut

106 dysbiosis (Poroyko et al. 2016), and such changes are reflected by an increase in the

107 Firmicutes/Bacteroidetes ratio, a preferential growth of the families Lachnospiraceae and

108 Rumninococcaceae, and a decrease in Lactobacillaceae (Poroyko et al. 2016). These

109 changes are in turn associated with increased gut permeability, increased systemic LPS 
110 levels, and ultimately with systemic inflammation, which can further precipitate and

111 maintain gut dysbiosis (Farre et al, 2018).

112 Given that both $\mathrm{HF}$ and $\mathrm{SF}$ are associated with gut dysbiosis and increased

113 inflammation (Farre et al. 2018), we hypothesized that the coexistence of both conditions

114 would result in a more marked alteration of the gut microbiome as compared with either

115 condition in isolation. To test this hypothesis, we analyzed changes in the gut microbiome

116 using a mouse model of HF and SF.

\section{RESULTS}

\section{Characterization of the microbiome}

119 We used a $16 \mathrm{~S}$ metabarcoding approach of the V3-V4 region and a computational

120 pipeline (see Materials and Methods) to assess the microbiome composition before and

121 after the treatment, in the different groups. The number of reads observed in each sample

122 ranged from 25,053 to 121,981 with a mean of 58,030.99 (Rarefaction curve, Figure S1.

123 Supplementary material). Overall, we identified 128 and 114 different taxa at the genus and

124 species levels, respectively. We classified $56.76 \%$ reads at the genus level, and the five

125 most abundant genera were Akkermansia, Alistipes, Bacteroides,

126 Lachnospiraceae_NK4136_group and an unclassified Muribaculaceae

127 (F.Muribaculaceae.UCG).

128 We produced Multidimensional scaling (MDS) plots based on the calculated beta

129 diversity (Figure 1). We observed that sample stratification was significantly driven by

130 Time $(\mathrm{P}<0.05$ Adonis, in all distance metrics except VAW_GUNifrac). This finding

131 suggests that the microbiota of both treated and control mice had evolved significantly 
132 during the four weeks of the experiment (Figure 1A). In addition, we observed that samples

133 clustered in two main enterotypes (Costea et al., 2018) (Figure 1B), which showed a

134 significant relationship with the Time variable according to Bray-Curtis dissimilarity (Chi-

135 square, $\mathrm{P}=3.228 \mathrm{e}-06$ ).

\section{Alpha diversity}

137 When considering all the samples together, the alpha diversity showed a tendency to

138 increase at the end of the experiment (Figure 2A), although not significantly $(\mathrm{P}>0.05$,

139 Wilcoxon). However, when comparing alpha diversity before and after the treatment within

140 each group, the control group (C) but not the others, had a significant increase in alpha

141 diversity (Figure 2B), whereas a trend toward a decrease in alpha diversity was noted for 142 HF.

143 We also observed differences in alpha diversity between mice subjected to the

144 different conditions. When considering only the samples after the experiment, we observed

145 that both HF and SF groups had significantly lower alpha diversity, as compared to animals

146 in $\mathrm{C}$ and $(\mathrm{HF}+\mathrm{SF})$ conditions (Figure 3A). When considering all samples, SF mice also

147 showed a significantly lower alpha diversity as compared to the other groups (Figure 3B).

148 This indicates the existence of differences in the basal microbiota before the start of the

149 experiment and highlights the need to focus on changes occurring during the experiment

150 rather than simply comparing final states.

\section{Changes in microbial composition}


152 We observed particular differences in abundance at different taxonomic levels

153 according to the fixed effect variables used in the two different linear models: In the first

154 linear model, all the samples were included and we studied the effect of both the Condition

155 and Time variables, whereas in the second linear model we included only the samples after

156 the experiment, and focused on the Condition and Change of weight variables (Table 1).

157 For instance, according to the first linear model we obtained 47 differential taxa at

158 the species level according to the Time variable. From these taxa, 11 were differentially

159 abundant according to both the Time and Condition variables: Bacteroides acidifaciens,

160 Bifidobacterium spp., $\quad$ F.Atopobiaceae.UCS, $\quad$ Bacteroides spp.,

161 Rikenellaceae_RC9_gut_group spp., F.Lachnospiraceae.UCS, Ruminococcaceae_UCG.014

162 spp., Ruminococcus spp., Allobaculum spp., Dubosiella spp. and Faecalibaculum spp.,

163 whereas 15 and 36 taxa were exclusively reported for Condition and Time separately,

164 respectively. (Supplementary material, Table 1).

165 On the other hand, applying the second linear model which only considered post-

166 exposure samples, we observed 32 significantly differentially abundant species according

167 to the Condition variable. Applying a multiple comparison test, the comparison with more

168 differences was $\mathrm{C}$ versus HF (Figure 4 and Supplementary material, Table 2). Notice that

169 we observed more changes when comparing HF and SF to healthy controls separately

170 instead of when mice were exposed to both conditions. This supports the above mentioned

171 results, in which the alpha diversity was lower in HF or SF separately when compared to

172 either $\mathrm{C}$ or $\mathrm{HF}+\mathrm{SF}$. 
173 Six taxa at the species level were significantly altered by both the Condition and

174 Change of weight variables: Ileibacterium valens, Mucispirillum schaedleri,

175 F.Peptococcaceae.UCS, Anaerotruncus spp., Ruminococcus spp. and Allobaculum spp.,

176 while 26 taxa were only significantly differentially abundant according to the Condition

177 variable (Table 2).

\section{DISCUSSION}

In the present study we used a mouse model to assess the impact on the gut

microbiome composition under conditions of HF and SF, and the combination of the two

181 perturbations, which is frequently present in patients suffering from heart failure who go on

182 to manifest sleep apnea. Overall, the study presents a clear separation between the samples

183 before and after the induction of the conditions, including among the mice in the control

184 group. This clustering may be produced by the anticipated evolution of the microbiome

185 over time, a phenomenon that has been reported in several other studies of the mouse gut

186 microbiome (Kim et al., 2019). Interestingly, an increase in the abundance of the family

187 Rikenellaceae, including the genus Alistipes (p-value 1.86e-09) in the post group samples

188 (after four weeks of experiment) emerged, taxa that have been previously reported as being

189 overrepresented in old mice and in elderly humans (Langille et al., 2014), (Claesson et al.,

190 2012).

191 The overall alpha diversity was increased in the post-exposure samples, but this

192 finding was only statistically significant in the control group. This suggests that species

193 richness is significantly higher after the four weeks of the experiment when the mice are

194 allowed to maintain their normal activities and are void of any of the experimental 
195 exposures, thereby corroborating earlier studies showing that older individuals exhibit more

196 species overall than juveniles (Mika et al., 2015). These results support the notion of an

197 evolving gut microbiome during mouse development and underscore the importance of

198 including samples taken at the start and at the end of the experiments to control for that

199 variation. Importantly, the variation in species richness differed among the treated groups,

200 wherein those exposed to only one of the relevant conditions displayed diminished species

201 richness. Our findings concur with previous studies that showed an alteration in the

202 microbiome in both HF and SF conditions and a decreased alpha diversity in HF patients

203 (Luedde et al., 2017), (Yuzefpolskaya et al., 2020).

The alteration of both Lachnospiraceae and Ruminococcaceae observed herein has

also been noted by others in both isolated HF or SF models (Luedde et al., 2017; Poroyko

206 et al., 2016). As mentioned, when applying a multiple comparison test considering only

207 post samples, the largest differences were between C and HF. One example of a species

208 that is altered is Bacteroides acidifaciens, which decreased in HF compared to C. B.

209 acidifaciens has been linked to decreased obesity and to improve insulin sensitivity (Yang

210 et al., 2017), is more abundant in individuals with high-fiber diets and acetate

211 supplementation, and has been reported to play a role in the regulation of the circadian

212 cycle in the heart (Marques et al., 2017; Yang et al., 2017). Since a disturbance in the

213 circadian cycle can cause cardiovascular complications (Duong et al. 2019, Zhang et al.

214 2020), a decrease in B. acidifaciens may serve as an indicator of increased risk for

215 deterioration of the underlying cardiac insufficiency. Interestingly, we also found this

216 species to be decreased in SF samples compared to controls ( $\mathrm{p}$-value 0.00025). This could

217 also be due to the same reason, since a disturbed circadian cycle can lead to fragmented 
218 sleep, or alternatively, SF could induce the changes in gut microbiome that then disrupt the

219 circadian cycle and elicit increased risk for cardiac decompensation in HF.

220 When we restrict our attention to the HF models, we observed an increase in the

221 species Ileibacterium valens and the genera Defluviitaleaceae_UCG.011,

222 Ruminococcaceae_UCG.014, Ruminococcus, Allobaculum and Oxalobacter compared to

223 healthy controls. On the other hand, in addition to the mentioned increase of $B$.

224 acidifaciens, we also observed a decrease in the species Mucispirillum schaedleri and the

225 genera Odoribacter, Alistipes, Mucispirillum, Lactococcus, Lachnoclostridium,

226 Anaerotruncus, Oscillibacter, Dubosiella and Anaeroplasma. In previous studies,

227 Ruminococcaceae_UCG.014 abundance was found as significantly positively associated

228 with serum trimethylamine N-oxide (TMAO) levels, which were associated with coronary

229 atherosclerotic plaque and increased cardiovascular disease risk (Gao et al., 2020). The

230 genus Ruminococcus was also found increased in HF models (Cui et al., 2018), and was

231 related to the inflammation that is observed in HF patients by the disruption of the gut

232 barrier through the translocation of gut bacterial DNA and/or endotoxins into the

233 bloodstream (Lataro et al., 2019). It is known that both a high-fat diet (calorie-dense

234 obesogenic) and aging cause inflammation in HF through an alteration of the microbiome

235 such as increasing the phylum Firmicutes, specifically the genus Allobaculum (Kain et al.,

236 2019), which in our study was found as significantly more abundant in HF than in C. Both

237 Alistipes and Oscillibacter were also reported in previous studies as decreased in chronic

238 HF patients (Cui et al., 2018).

239 Regarding the SF models, we observed increased Muribaculum and

240 Faecalibaculum at the genus level, and decreased B. acidifaciens at the species level and 
241 Lactococcus, Lachnoclostridium, Harryflintia and Dubosiella at the genus level. It is

242 known that melatonin plays a beneficial role in the stabilization of the circadian rhythm

243 (Turek \& Gillette, 2004) and a recent study reported that melatonin inhibits

244 Faecalibaculum (Hong et al., 2020; Turek \& Gillette, 2004). In our study we observed an

245 increase of this genus. Therefore, this reduction can be an indicator of reduced melatonin

246 bioavailability, and consequently reflect a destabilization of the circadian rhythm in SF-

247 exposed mice. Our results also support past findings, whereby the genus Lachnoclostridium

248 was reported as underrepresented in chronic intermittent hypoxia in guinea-pigs (Lucking

249 et al., 2018). Hypoxia can be a consequence of a sleep disorder such as sleep apnea. We

250 also found in the bibliography that Harryflintia was positively associated with a circadian

251 clock gene (Cry1) whose mutations were related to sleep disorders (Patke et al., 2017).

252 When considering the coexistence of both HF and SF conditions compared with

253 control mice, we detected only a very small number of differences, namely an increase of

254 Muribaculum and a decrease of Bilophila. Neither of these genera was previously related to

255 these conditions. Overall, contrary to our initial hypothesis, our results show no strong

256 synergism between the HF and SF conditions as their individual effects were not

257 potentiated when applied in combination. Rather, the changes when the two conditions

258 were combined were less apparent than when applying each condition individually, both in

259 terms of changes in the alpha diversity and in the number of altered taxa. This suggests

260 some level of antagonism between the two conditions, which may influence the

261 microbiome in opposite directions, resulting in some of these effects cancelling each other

262 out.

\section{CONCLUSION}


265 heart failure and of sleep fragmentation when these conditions are evaluated separately.

266 The inflammation observed in HF and SF could be mediated by alterations in abundance of

267 particular taxa. Finally, when the two conditions were applied concomitantly, the

268 alterations in the gut microbiome were milder and virtually disappeared, suggesting some

269 level of antagonism between the effects for HF and SF.

270 MATERIALS AND METHODS

271 Animal models experiments

272 Forty male mice (C57BL/6J; 10 weeks old; $12 \mathrm{~h}$ light/dark cycle; water/food ad

273 libitum) were randomly allocated into four groups ( $\mathrm{n}=10$ each). In two groups, the mice

274 were allowed to sleep normally: healthy control (C) and heart failure (HF). In two groups

275 (SF, HF+SF), SF was imposed, and in two groups (HF, HF+SF) heart failure was induced.

276 The animal experiment including the setting of the HF and SF models were approved by

277 the institution ethical committee and has been recently described in detail (Cabrera-

278 Aguilera et al, 2020).

HF was induced by continuous infusion of isoproterenol (Cabrera-Aguilera et al,

280 2020). Briefly, mice were anesthetized by isoflurane inhalation and an osmotic minipump

281 (Alzet, model 1004) was implanted subcutaneously in the flank. The pump delivered 30

$282 \mathrm{mg} / \mathrm{kg}$ per day of isoproterenol (Sigma Aldrich; in sterile $0.9 \% \mathrm{NaCl}$ solution) for 28 days.

283 Buprenorphine $(0.3 \mathrm{mg} / \mathrm{kg}$, i.p.) was administered 10 minutes before surgery and after 24

284 hours, and the suture was removed 7 days after surgery. Healthy animals were subjected to

285 the same protocol with the only difference being that no isoproterenol was dissolved into 
286 the $0.9 \% \mathrm{NaCl}$ pump medium. As described elsewhere (Cabrera-Aguilera et al, 2020), the

287 effectiveness of the HF model in these animals was assessed by echocardiography after 28

288 days of isoproterenol infusion, confirming that mice in the HF groups had significant

289 increases in left ventricular end-diastolic and LVESD and end-systolic diameter as well as

290 significant reductions in left ventricular ejection fraction and fraction shortening.

291 Two days after surgery, SF was induced daily by means of a previously described

292 and validated device for mice (Lafayette Instruments, Lafayette, IN), which is based on

293 intermittent tactile stimulation with no human intervention. Sleep arousals were induced by

294 a mechanical near-silent motor with a horizontal bar sweeping just above the cage floor

295 from one side to the other side in the standard mouse laboratory cage. Each sweep was

296 applied in 2-minute intervals during the murine sleep period ( 8 a.m. to 8 p.m.) for 28 days

297 (until day 30 from surgery) (Cabrera-Aguilera et al, 2020).

At the end of the 4-week experiment (HF, SF, HF+SF and control), fecal

of the animal and were immediately frozen at $-80^{\circ} \mathrm{C}$ and stored until analyzed.

\section{DNA extraction, library preparation and sequencing}

DNA was extracted from mice fecal individual samples using the DNeasy

303 PowerLyzer PowerSoil Kit (Qiagen, ref. QIA12855) following the manufacturer's

304 instructions. After adding mice stool samples to the PowerBead Tubes, $750 \mu 1$ of

305 PowerBead Solution and $60 \mu \mathrm{l}$ of Solution C1 were added, and samples were vortexed

306 briefly and incubated at $70^{\circ} \mathrm{C}$ with shaking $(700 \mathrm{rpm})$ for $10 \mathrm{~min}$. The extraction tubes were

307 then agitated twice in a 96-well plate using Tissue lyser II (Qiagen) at $30 \mathrm{~Hz} / \mathrm{s}$ for $5 \mathrm{~min}$. 
308 Tubes were centrifuged at 10,000 $\mathrm{g}$ for $3 \mathrm{~min}$ and the supernatant was transferred to a clean

309 tube. $250 \mu \mathrm{l}$ of Solution C2 were added, and samples were vortexed for $5 \mathrm{~s}$ and incubated

310 on ice for $10 \mathrm{~min}$. After $1 \mathrm{~min}$ centrifugation at $10,000 \mathrm{~g}$, the supernatant was transferred to

311 a clean tube, $200 \mu 1$ of Solution C3 were added, and samples were vortexed for $5 \mathrm{~s}$ and

312 incubated on ice for $10 \mathrm{~min}$ again. $750 \mu \mathrm{l}$ of the supernatant were transferred into a clean

313 tube after $1 \mathrm{~min}$ centrifugation at 10,000 g. Then, 1,200 $\mu$ l of Solution $\mathrm{C} 4$ were added to the

314 supernatant, samples were mixed by pipetting up and down, and $675 \mu 1$ were loaded onto a

315 spin column and centrifuge at $10,000 \mathrm{~g}$ for $1 \mathrm{~min}$, discarding the flow through. This step

316 was repeated three times until all samples had passed through the column. $500 \mu$ of

317 Solution C5 were added onto the column and samples were centrifuged at 10,000 g for 1

318 min, the flow through was discarded and one extra minute centrifugation at 10,000 $\mathrm{g}$ was

319 done to dry the column. Finally, the column was placed into a new $2 \mathrm{ml}$ tube to the final

320 elution with $50 \mu \mathrm{l}$ of Solution C6 and centrifugation at 10,000 g for $30 \mathrm{~s}$.

321 Four $\mu 1$ of each DNA sample were used to amplify the V3-V4 regions of the

322 bacterial $16 \mathrm{~S}$ ribosomal RNA gene, using the following universal primers in a limited cycle 323 PCR:

324 V3-V4-Forward (5'-

325 TCGTCGGCAGCGTCAGATGTGTATAAGAGACAGCCTACGGGNGGCWGCAG-3')

326 and V3-V4-Reverse (5'-

327 GTCTCGTGGGCTCGGAGATGTGTATAAGAGACAGGACTACHVGGGTATCTAAT

328 CC-3'). 
330 sequencing phases by adding various numbers of bases (from 0 to 3 ) as spacers to both

331 forward and reverse primers (we used a total of 4 forward and 4 reverse primers). The PCR

332 was performed in $10 \mu \mathrm{l}$ volume reactions with $0.2 \mu \mathrm{M}$ primer concentration and using the

333 Kapa HiFi HotStart Ready Mix (Roche, ref. KK2602). Cycling conditions were initial

334 denaturation of $3 \mathrm{~min}$ at $95^{\circ} \mathrm{C}$ followed by 20 cycles of $95^{\circ} \mathrm{C}$ for $30 \mathrm{~s}, 55^{\circ} \mathrm{C}$ for $30 \mathrm{~s}$, and

$33572{ }^{\circ} \mathrm{C}$ for $30 \mathrm{~s}$, ending with a final elongation step of 5 min at $72{ }^{\circ} \mathrm{C}$.

336 After the first PCR step, water was added to a total volume of $50 \mu 1$ and reactions

337 were purified using AMPure XP beads (Beckman Coulter) with a 0.9X ratio according to

338 manufacturer's instructions. PCR products were eluted from the magnetic beads with $32 \mu 1$

339 of Buffer EB (Qiagen) and $30 \mu 1$ of the eluate were transferred to a fresh 96-well plate. The

340 primers used in the first PCR contain overhangs allowing the addition of full-length

341 Nextera adapters with barcodes for multiplex sequencing in a second PCR step, resulting in

342 sequencing ready libraries. To this end, $5 \mu 1$ of the first amplification were used as template

343 for the second PCR with Nextera XT v2 adaptor primers in a final volume of $50 \mu 1$ using

344 the same PCR mix and thermal profile as for the first PCR but only 8 cycles. After the

345 second PCR, $25 \mu$ of the final product was used for purification and normalization with

346 SequalPrep normalization kit (Invitrogen), according to the manufacturer's protocol.

347 Libraries were eluted in $20 \mu \mathrm{l}$ and pooled for sequencing.

348 Final pools were quantified by qPCR using Kapa library quantification kit for

349 Illumina Platforms (Kapa Biosystems) on an ABI 7900HT real-time cycler (Applied

350 Biosystems). Sequencing was performed in Illumina MiSeq with $2 \times 300$ bp reads using v3

351 chemistry with a loading concentration of $18 \mathrm{pM}$. To increase the diversity of the sequences 
$35210 \%$ of $\mathrm{PhIX}$ control libraries were spiked in.

354 Human Microbiome Project (HM-276D and HM-277D), each contained genomic DNA of

355 ribosomal operons from 20 bacterial species. Mock DNAs were amplified and sequenced in

356 the same manner as all other murine stool samples. Negative controls of the DNA

357 extraction and PCR amplification steps were also included in parallel, using the same

358 conditions and reagents. These negative controls provided no visible band or quantifiable

359 DNA amounts by Bioanalyzer, whereas all of our samples provided clearly visible bands

360 after 20 cycles.

\section{Microbiome analysis}

363 (amplicon sequence variants) table (Nearing et al., 2018). First, the sequence quality

364 profiles of forward and reverse sequencing reads were examined using the

365 plotQualityProfile function of dada2. Based on these profiles, low-quality sequencing reads

366 were filtered out and the remaining reads were trimmed at positions 285 (forward) and 240

367 (reverse). The first 10 nucleotides corresponding to the adaptors were also trimmed, using

368 the filterAndTrim function with the following parameters:

“filterAndTrim(fnFs, filtFs, fnRs, filtRs, truncLen=c(285,240), $\max N=0$,

$\operatorname{maxEE}=c(10,10)$, trunc $\mathrm{Q}=1, \mathrm{rm} \cdot \mathrm{phix}=\mathrm{TRUE}$, trimLeft $=\mathrm{c}(10,10)$, compress $=$ TRUE, 
373 redundant comparisons (dereplication), sample sequences were inferred (from a pre-

374 calculated matrix of estimated learning error rates) and paired reads were merged to obtain

375 full denoised sequences. From these, chimeric sequences were removed. Taxonomy was

376 assigned to ASVs using the SILVA 16s rRNA database (v. 132) (Quast et al., 2013). Next, a

377 phylogenetic tree representing the taxa found in the sample dataset was reconstructed by

378 using the phangorn (v. 2.5.5) (Schliep, 2011) and Decipher R packages (v 2.10.2) (Wright

379 et al., 2016). We integrated the information from the ASV table, Taxonomy table,

380 phylogenetic tree and metadata (information relative to the samples such as the time, batch

381 of the DNA extraction and change of weight) to create a phyloseq (v. 1.26.1) object

382 (McMurdie \& Holmes, 2013). Positive and negative sequencing controls (mock

383 communities and water samples, respectively) sequenced and included in the ASV table

384 were removed from subsequent statistical analyses.

385 The metadata consisted of 11 variables: batchDNAextraction, sample, Time

386 (indicating whether samples were taken prior to or post treatment); Box;

387 SF.NORMAL.SLEEP (Sleep fragmentation or normal sleep); Animal; Pump (What

388 substance was injected, Isoproterenol or Saline - control); Initial_weight; Final_weight; and

389 Initial ecography (the value of which was "Ready" for all the animals). We created a new

390 variable called Condition corresponding to the four different treatment groups: C, HF, SF 391 and $\mathrm{HF}+\mathrm{SF}$.

393 diversity (between samples) were characterized. Using the estimate_richness function of

394 the phyloseq package we calculated the alpha diversity metrics including Observed.index, 
395 Chao1, Shannon, Simpson and InvSimpson indices. Regarding the different beta-diversity

396 metrics, we used the Phyloseq and Vegan (v. 2.5-6) (Oksanen et al. 2019) packages to

397 characterize nine distances based on differences in taxonomic composition of the samples

398 including JSD, Weighted-Unifrac, Unweighted-unifrac, VAW-Gunifrac, a0-Gunifrac,

399 a05_Gunifrac, Bray, Jaccard and Canberra. We also computed Aitchison distance (Gloor et

400 al., 2017) using the cmultRepl and codaSeq.clr functions from the CodaSeq (v. 0.99.6)

401 (Gloor \& Reid, 2016) and zCompositions (v.1.3.4) (Palarea-Albaladejo \& Martín-

402 Fernández, 2015) packages.

Normalization was performed by transforming the data to relative abundances, and

404 samples containing fewer than 950 reads were discarded and taxa that appeared in fewer

405 than $5 \%$ of the samples at low abundances were filtered out:

“prune_samples( sample_sums(object) $>=950$, object $) "$

"filter_taxa(object, function $(\mathrm{x}) \operatorname{sum}(\mathrm{x}>0.001)>(0.05 *$ length $(\mathrm{x}))$, prune $=$ TRUE)"

\section{Statistical analysis}

411 performed using one-way ANOVA. Comparison of echocardiographic data between all

412 groups at day 30 was performed using two-way ANOVA followed by the Student-

413 Newman-Keuls comparison method. The data is presented as mean $\pm \mathrm{SEM}$.

We used the Partitioning Around Medoid (PAM) algorithm (Reynolds et al., 2006),

415 as implemented in the cluster library (v. 2.0.7-1), to explore clustering of the samples. We 
416 further evaluated this, performing a Permutational Multivariate Analysis of Variance

417 (PERMANOVA) using the ten-distance metrics mentioned above, and the adonis function

418 from the Vegan R package (v. 2.5-6) (Oksanen et al. 2019). The Time and Box variables

419 were considered as covariates.

420 To identify taxonomic features (Phylum, Class, Order, Family, Genus and Species)

421 that show significantly different abundances among studied conditions, we used linear

422 models, as implemented in the $\mathrm{R}$ package lme4 (v. 1.1-21) (Bates et al. 2015). Two

423 different linear models were built: In the first one, the fixed effects were the Condition and

424 Time variables and the random effects were the batch of the DNA extraction and the 425 animal, where this last one is an indicator of a paired analysis (tax_element $\sim$ Condition +

426 Time + (1| batchDNAextraction $)+(1 \mid$ Animal $))$. On the other hand, in the second linear

427 model we included only post samples and instead of the Time variable, we used as a fixed

428 effect the Change of weight of the mouse models (Final_weight - Initial_weight). In this

429 case we only used as a random effect the batch (tax_element $~$ Condition_POST_only +

430 Change_of_weight $+(1$ batchDNAextraction $))$.

Analysis of Variance (ANOVA) was applied to assess the significance for each of

432 the fixed effects included in the models using the Car R package (v. 3.0-6) (Fox et al.,

433 2013). To assess particular differences between groups we performed multiple comparisons

434 to the results obtained in the linear models using the multcomp $\mathrm{R}$ package (v. 1.4-12)

435 (Hothorn et al., 2008). We applied Bonferroni as a multiple testing correction. Statistical

436 significance was defined when $\mathrm{p}$ values were lower than 0.05 in all the analyses. 


\section{ACKNOWLEDGMENTS}

439 The authors wish to thank Mrs. Elisabeth Urrea and Mr. Miguel A. Rodriguez-

440 Lazaro for their excellent technical assistance.

442 Data availability:

443 Raw sequence data can be found in the Sequence Read Archive with the Bioproject 444 accession code: PRJNA662468

\section{Funding:}

446 IC-A was supported by CONICYT PFCHA - Chilean Doctorate Fellowship 2017; Grant 447 No. 72180089. RF was supported in part by the Spanish Ministry of Economy and 448 Competitiveness (SAF2017-85574-R). DG was supported in part by National Institutes of 449 Health grants HL130984 and HL140548. TG group acknowledges support from the 450 Spanish Ministry of Science and Innovation for grant PGC2018-099921-B-I00, cofounded 451 by European Regional Development Fund (ERDF); from the CERCA Programme / 452 Generalitat de Catalunya; from the Catalan Research Agency (AGAUR) SGR423. from the 453 European Union's Horizon 2020 research and innovation programme under the grant 454 agreement ERC-2016-724173; and from Instituto de Salud Carlos III (INB Grant, 455 PT17/0009/0023 - ISCIII-SGEFI/ERDF).

460 Authors contribution:

461 O. Khannous-Lleiffe, J.R. Willis and E. Saus carried out the microbiota analysis. I. 462 Cabrera-Aguilera was in charge of the animal model experiments. I. Almendros, R. Farré 463 and D. Gozal participated in data interpretation and scientific discussion. T. Gabaldón 
bioRxiv preprint doi: https://doi.org/10.1101/2020.09.11.294447; this version posted September 15,2020 . The copyright holder for this preprint (which was not certified by peer review) is the author/funder, who has granted bioRxiv a license to display the preprint in perpetuity. It is made available under aCC-BY-NC 4.0 International license.

464 designed and supervised the microbiota analysis and discussion. Nuria Farré conceived the

465 study and supervised the whole research. All authors participated in the manuscript 466 preparation. 


\section{REFERENCES}

468 Cabrera-Aguilera I, Benito B, Tajes M, et al. Chronic Sleep Fragmentation Mimicking 469 Sleep Apnea Does Not Worsen Left-Ventricular Function in Healthy and Heart Failure Mice. Front Neurol. 2020;10:1364. doi:10.3389/fneur.2019.01364

471 Callahan, B. J., McMurdie, P. J., Rosen, M. J., Han, A. W., Johnson, A. J. A., \& Holmes, S. 472 P. (2016). DADA2: High-resolution sample inference from Illumina amplicon data. $473 \quad$ Nature Methods, 13(7), 581-583.

474 Camps-Vilaró A, Delgado-Jiménez JF, Farré N, et al. Estimated Population Prevalence of 475 Heart Failure with Reduced Ejection Fraction in Spain, According to DAPA-HF Study Criteria. J Clin Med. 2020;9(7):E2089. Published 2020 Jul 3. doi:10.3390/jcm9072089.

478 Claesson, M. J., Jeffery, I. B., Conde, S., Power, S. E., O’Connor, E. M., Cusack, S., 479 Harris, H. M. B., Coakley, M., Lakshminarayanan, B., O’Sullivan, O., Fitzgerald, G. 480 F., Deane, J., O’Connor, M., Harnedy, N., O’Connor, K., O’Mahony, D., van 481 Sinderen, D., Wallace, M., Brennan, L., ... O’Toole, P. W. (2012). Gut microbiota 482 composition correlates with diet and health in the elderly. Nature, 488(7410), 178-184. 483 Costea, P. I., Hildebrand, F., Arumugam, M., Bäckhed, F., Blaser, M. J., Bushman, F. D., 484 de Vos, W. M., Ehrlich, S. D., Fraser, C. M., Hattori, M., Huttenhower, C., Jeffery, I. 485 B., Knights, D., Lewis, J. D., Ley, R. E., Ochman, H., O’Toole, P. W., Quince, C., 486 Relman, D. A., ... Bork, P. (2018). Enterotypes in the landscape of gut microbial 487 community composition. Nature Microbiology, 3(1), 8-16.

488 Cui, X., Ye, L., Li, J., Jin, L., Wang, W., Li, S., Bao, M., Wu, S., Li, L., Geng, B., Zhou, 489 X., Zhang, J., \& Cai, J. (2018). Metagenomic and metabolomic analyses unveil 
490 dysbiosis of gut microbiota in chronic heart failure patients. Scientific Reports, 8(1),

491635.

492 Cowie MR, Gallagher AM. Sleep Disordered Breathing and Heart Failure: What Does the 493 Future Hold? JACC Heart Fail. 2017 Oct;5(10):715-723. doi: 494 10.1016/j.jchf.2017.06.016. Epub 2017 Sep 6. PMID: 28888522.

495 Duong ATH, Reitz CJ, Louth EL, Creighton SD, Rasouli M, Zwaiman A, Kroetsch JT, 496 Bolz SS, Winters BD, Bailey CDC, Martino TA. The Clock Mechanism Influences 497 Neurobiology and Adaptations to Heart Failure in Clock- $\Delta 19 / \Delta 19$ Mice With 498 Implications for Circadian Medicine. Sci Rep. 2019 Mar21;9(1):4994. doi: 10.1038/s41598-019-41469-7. PMID: 30899044; PMCID: PMC6428811.

500 Farré N, Vela E, Clèries M, et al. Real world heart failure epidemiology and outcome: A 501 population-based analysis of 88,195 patients. PLoS One. 2017;12(2):e0172745. 502 Published 2017 Feb 24. doi:10.1371/journal.pone.0172745

503 Farré N, Farré R, Gozal D. Sleep Apnea Morbidity: A Consequence of Microbial-Immune 504 Cross-Talk?. Chest. 2018;154(4):754-759. doi:10.1016/j.chest.2018.03.001.

505 Fox, J., Friendly, M., \& Weisberg, S. (2013). Hypothesis Tests for Multivariate Linear 506 Models Using the car Package. In The R Journal (Vol. 5, Issue 1, p. 39). $507 \quad$ https://doi.org/10.32614/rj-2013-004

508 Gao, J., Yan, K.-T., Wang, J.-X., Dou, J., Wang, J., Ren, M., Ma, J., Zhang, X., \& Liu, Y. 509 (2020). Gut microbial taxa as potential predictive biomarkers for acute coronary 510 syndrome and post-STEMI cardiovascular events. Scientific Reports, 10(1), 2639.

511 Genth-Zotz S, von Haehling S, Bolger AP, et al. Pathophysiologic quantities of endotoxin512 induced tumor necrosis factor-alpha release in whole blood from patients with chronic 
513 heart failure. Am J Cardiol. 2002;90(11):1226-1230. doi:10.1016/s0002$5149149(02) 02839-4$.

515 Gloor, G. B., Macklaim, J. M., Pawlowsky-Glahn, V., \& Egozcue, J. J. (2017). Microbiome

516 Datasets Are Compositional: And This Is Not Optional. Frontiers in Microbiology, 8. $517 \quad$ https://doi.org/10.3389/fmicb.2017.02224

518 Gloor, G. B., \& Reid, G. (2016). Compositional analysis: a valid approach to analyze 519 microbiome high-throughput sequencing data. Canadian Journal of Microbiology, $520 \quad 62(8), 692-703$.

521 Hong, F., Pan, S., Xu, P., Xue, T., Wang, J., Guo, Y., Jia, L., Qiao, X., Li, L., \& Zhai, Y. 522 (2020). Melatonin Orchestrates Lipid Homeostasis through the Hepatointestinal 523 Circadian Clock and Microbiota during Constant Light Exposure. Cells , 9(2). $524 \quad$ https://doi.org/10.3390/cells9020489

525 Hothorn, T., Bretz, F., \& Westfall, P. (2008). Simultaneous inference in general parametric 526 models. Biometrical Journal. Biometrische Zeitschrift, 50(3), 346-363.

527 Javaheri S, Brown LK, Khayat RN. Update on Apneas of Heart Failure With Reduced 528 Ejection Fraction: Emphasis on the Physiology of Treatment: Part 2: Central Sleep 529 Apnea. Chest. 2020 Jun;157(6):1637-1646. doi: 10.1016/j.chest.2019.12.020. Epub $530 \quad 2020$ Jan 17. PMID: 31958442.

531 Kain, V., Van Der Pol, W., Mariappan, N., Ahmad, A., Eipers, P., Gibson, D. L., Gladine, 532 C., Vigor, C., Durand, T., Morrow, C., \& Halade, G. V. (2019). Obesogenic diet in 533 aging mice disrupts gut microbe composition and alters neutrophil:lymphocyte ratio, 534 leading to inflamed milieu in acute heart failure. FASEB Journal: Official Publication 535 of the Federation of American Societies for Experimental Biology, 33(5), 6456-6469.

536 Kim, S. J., Kim, S.-E., Kim, A.-R., Kang, S., Park, M.-Y., \& Sung, M.-K. (2019). Dietary 
537 fat intake and age modulate the composition of the gut microbiota and colonic 538 inflammation in C57BL/6J mice. BMC Microbiology, 19(1), 193.

539 Ko CY, Liu QQ, Su HZ, et al. Gut microbiota in obstructive sleep apnea-hypopnea 540 syndrome: disease-related dysbiosis and metabolic comorbidities. Clin Sci (Lond). 2019;133(7):905-917. Published 2019 Apr 12. doi:10.1042/CS20180891

542 Langille, M. G., Meehan, C. J., Koenig, J. E., Dhanani, A. S., Rose, R. A., Howlett, S. E., 543 \& Beiko, R. G. (2014). Microbial shifts in the aging mouse gut. Microbiome, 2(1), 50.

544 Lataro, R. M., Imori, P. F. M., Santos, E. S., Silva, L. E. V., Duarte, R. T. D., Silva, C. A. 545 A., Falcão, J. P., Paton, J. F. R., \& Salgado, H. C. (2019). Heart failure developed after 546 myocardial infarction does not affect gut microbiota composition in the rat. American 547 Journal of Physiology. Gastrointestinal and Liver Physiology, 317(3), G342-G348.

548 Lucking, E. F., O’Connor, K. M., Strain, C. R., Fouhy, F., Bastiaanssen, T. F. S., Burns, D. 549 P., Golubeva, A. V., Stanton, C., Clarke, G., Cryan, J. F., \& O’Halloran, K. D. (2018).

550 Chronic intermittent hypoxia disrupts cardiorespiratory homeostasis and gut 551 microbiota composition in adult male guinea-pigs. EBioMedicine, 38, 191-205.

552 Luedde, M., Winkler, T., Heinsen, F.-A., Rühlemann, M. C., Spehlmann, M. E., Bajrovic, 553 A., Lieb, W., Franke, A., Ott, S. J., \& Frey, N. (2017). Heart failure is associated with 554 depletion of core intestinal microbiota. ESC Heart Failure, 4(3), 282-290.

555 Marques, F. Z., Nelson, E., Chu, P.-Y., Horlock, D., Fiedler, A., Ziemann, M., Tan, J. K., 556 Kuruppu, S., Rajapakse, N. W., El-Osta, A., Mackay, C. R., \& Kaye, D. M. (2017). 557 High-Fiber Diet and Acetate Supplementation Change the Gut Microbiota and Prevent 558 the Development of Hypertension and Heart Failure in Hypertensive Mice. $559 \quad$ Circulation, 135(10), 964-977.

560 Mashaqi S, Gozal D. Obstructive Sleep Apnea and Systemic Hypertension: Gut Dysbiosis 
562 Mayerhofer CCK, Kummen M, Holm K, et al. Low fibre intake is associated with gut 563 microbiota alterations in chronic heart failure. ESC Heart Fail. 2020;7(2):456-466. 564 doi:10.1002/ehf2.12596.

565 McMurdie, P. J., \& Holmes, S. (2013). phyloseq: an R package for reproducible interactive 566 analysis and graphics of microbiome census data. PloS One, 8(4), e61217.

567 Mika, A., Van Treuren, W., González, A., Herrera, J. J., Knight, R., \& Fleshner, M. (2015).

568 Exercise is More Effective at Altering Gut Microbial Composition and Producing 569 Stable Changes in Lean Mass in Juvenile versus Adult Male F344 Rats. PloS One, $570 \quad 10(5), \mathrm{e} 0125889$.

571 Moreno-Indias I, Torres M, Montserrat JM, et al. Intermittent hypoxia alters gut microbiota 572 diversity in a mouse model of sleep apnoea. Eur Respir J. 2015;45(4):1055-1065. doi:10.1183/09031936.00184314.

574 Nearing, J. T., Douglas, G. M., Comeau, A. M., \& Langille, M. G. I. (2018). Denoising the 575 Denoisers: an independent evaluation of microbiome sequence error-correction $576 \quad$ approaches. PeerJ, 6, e5364.

577 Palarea-Albaladejo, J., \& Martín-Fernández, J. A. (2015). zCompositions — R package for 578 multivariate imputation of left-censored data under a compositional approach. In 579 Chemometrics and Intelligent Laboratory Systems (Vol. 143, pp. 85-96). $580 \quad$ https://doi.org/10.1016/j.chemolab.2015.02.019

581 Patke, A., Murphy, P. J., Onat, O. E., Krieger, A. C., Özçelik, T., Campbell, S. S., \& 582 Young, M. W. (2017). Mutation of the Human Circadian Clock Gene CRY1 in 583 Familial Delayed Sleep Phase Disorder. Cell, 169(2), 203-215.e13.

584 Poroyko, V. A., Carreras, A., Khalyfa, A., Khalyfa, A. A., Leone, V., Peris, E., Almendros, 
585

586

587

588

589

590

591

592

593

594

595

596

597

598

599

600

601

602

603

604

605

606

607

608

I., Gileles-Hillel, A., Qiao, Z., Hubert, N., Farré, R., Chang, E. B., \& Gozal, D. (2016).

Chronic Sleep Disruption Alters Gut Microbiota, Induces Systemic and Adipose Tissue Inflammation and Insulin Resistance in Mice. In Scientific Reports (Vol. 6, Issue 1). https://doi.org/10.1038/srep35405

Quast, C., Pruesse, E., Yilmaz, P., Gerken, J., Schweer, T., Yarza, P., Peplies, J., \& Glöckner, F. O. (2013). The SILVA ribosomal RNA gene database project: improved data processing and web-based tools. Nucleic Acids Research, 41(Database issue), D590-D596.

Reynolds, A. P., Richards, G., de la Iglesia, B., \& Rayward-Smith, V. J. (2006). Clustering Rules: A Comparison of Partitioning and Hierarchical Clustering Algorithms. Journal of Mathematical Modelling and Algorithms, 5(4), 475-504.

Sandek A, Bauditz J, Swidsinski A, et al. Altered intestinal function in patients with chronic heart failure. J Am Coll Cardiol. 2007;50(16):1561-1569. doi:10.1016/j.jacc.2007.07.016.

Schliep, K. P. (2011). phangorn: phylogenetic analysis in R. In Bioinformatics (Vol. 27, Issue 4, pp. 592593). https://doi.org/10.1093/bioinformatics/btq706Suzuki T, Heaney LM, Bhandari SS, Jones DJ, Ng LL. Trimethylamine N-oxide and prognosis in acute heart failure. Heart. 2016;102(11):841-848. doi:10.1136/heartjnl-2015-308826.

Tang WH, Kitai T, Hazen SL. Gut microbiota in cardiovascular health and disease. Circ Res. 2017;120(7):1183-1196.

Tremaroli V, Bäckhed F. Functional interactions between the gut microbiota and host metabolism. Nature. 2012;489(7415):242-249. doi:10.1038/nature11552

Tripathi A, Melnik AV, Xue J, et al. Intermittent Hypoxia and Hypercapnia, a Hallmark of Obstructive Sleep Apnea, Alters the Gut Microbiome and Metabolome. mSystems. 
610 Turek, F. W., \& Gillette, M. U. (2004). Melatonin, sleep, and circadian rhythms: rationale

611 for development of specific melatonin agonists. Sleep Medicine, 5(6), 523-532.

612 Willis, J. R., González-Torres, P., Pittis, A. A., Bejarano, L. A., Cozzuto, L., Andreu613 Somavilla, N., Alloza-Trabado, M., Valentín, A., Ksiezopolska, E., Company, C.,

614 Onywera, H., Montfort, M., Hermoso, A., Iraola-Guzmán, S., Saus, E., Labeeuw, A., 615 Carolis, C., Hecht, J., Ponomarenko, J., \& Gabaldón, T. (2018). Citizen science charts 616 two major "stomatotypes" in the oral microbiome of adolescents and reveals links with 617 habits and drinking water composition. Microbiome, 6(1), 218.

618 Wright, E., Erik, \& Wright, S. (2016). Using DECIPHER v2.0 to Analyze Big

619 Biological Sequence Data in R. In The R Journal (Vol. 8, Issue 1, p. 352).

620 https://doi.org/10.32614/rj-2016-025

621

622 Yang, J.-Y., Lee, Y.-S., Kim, Y., Lee, S.-H., Ryu, S., Fukuda, S., Hase, K., Yang, C.-S., 623 Lim, H. S., Kim, M.-S., Kim, H.-M., Ahn, S.-H., Kwon, B.-E., Ko, H.-J., \& Kweon, 624 M.-N. (2017). Gut commensal Bacteroides acidifaciens prevents obesity and improves 625 insulin sensitivity in mice. Mucosal Immunology, 10(1), 104-116.

626 Yuzefpolskaya, M., Bohn, B., Nasiri, M., Zuver, A. M., Onat, D. D., Royzman, E. A., 627 Nwokocha, J., Mabasa, M., Pinsino, A., Brunjes, D., Gaudig, A., Clemons, A., Trinh, 628 P., Stump, S., Giddins, M. J., Topkara, V. K., Garan, A. R., Takeda, K., Takayama, H., 629 ... Demmer, R. T. (2020). Gut microbiota, endotoxemia, inflammation, and oxidative 630 stress in patients with heart failure, left ventricular assist device, and transplant. The 631 Journal of Heart and Lung Transplantation: The Official Publication of the 632 International Society for Heart Transplantation. 
633 https://doi.org/10.1016/j.healun.2020.02.004.

634 Zhang J, Chatham JC, Young ME. Circadian Regulation of Cardiac Physiology: Rhythms

635 That Keep the Heart Beating. Annu Rev Physiol. 2020 Feb 10;82:79-101. doi:

636 10.1146/annurev-physiol-020518-114349. Epub 2019 Oct 7. PMID: 31589825.

642 Table 1. Differential abundance analysis findings. A) Linear model including all the

643 samples; Fixed effects: Condition and Time variable. Random effects: Batch DNA

644 extraction and Animal (to indicate a paired analysis). B) Linear model taking into

645 consideration only post samples; Fixed effects: Condition and Change of weight variables.

646 Random effect: Batch DNA extraction.

648 A)

\begin{tabular}{|l|c|c|c|c|c|c|}
\hline Variable \Rank & Phylum & Class & Order & Family & Genus & Species \\
\hline Condition & 3 & 5 & 5 & 10 & 23 & 26 \\
\hline Time & 4 & 9 & 10 & 19 & 41 & 47 \\
\hline
\end{tabular}

649 
bioRxiv preprint doi: https://doi.org/10.1101/2020.09.11.294447; this version posted September 15,2020 . The copyright holder for this preprint (which was not certified by peer review) is the author/funder, who has granted bioRxiv a license to display the preprint in perpetuity. It is made available under aCC-BY-NC 4.0 International license.

650 B)

\begin{tabular}{|l|c|c|c|c|c|c|}
\hline Variable \Rank & Phylum & Class & Order & Family & Genus & Species \\
\hline Condition & 1 & 2 & 4 & 14 & 30 & 32 \\
\hline Weight change & 1 & 1 & 1 & 3 & 9 & 9 \\
\hline
\end{tabular}

651

652 
653 Table 2. Summary of the p-values corresponding to the 32 significantly differentially

654 abundant taxa at species level according to both Condition and Change of weight variables.

\begin{tabular}{|c|c|c|}
\hline & Condition & $\begin{array}{l}\text { Change } \\
\text { weight }\end{array}$ \\
\hline Bacteroides acidifaciens & 0.00015 & \\
\hline Ileibacterium valens & 0.00113 & 0.00062 \\
\hline Mucispirillum schaedleri & 0.00125 & 0.03626 \\
\hline Olsenella spp. & $2.79 \mathrm{e}-25$ & \\
\hline Bacteroides spp. & 0.00904 & \\
\hline Odoribacter spp. & 0.03183 & \\
\hline Muribaculum spp. & 0.01244 & \\
\hline Prevotellaceae UCG.001 spp. & 0.03238 & \\
\hline Alistipes spp. & $3.44 \mathrm{e}-05$ & \\
\hline O.Bacteroidales.UCS & 0.00117 & \\
\hline Mucispirillum spp. & 0.00408 & \\
\hline Lactococcus spp. & 0.00262 & \\
\hline Defluviitaleaceae_UCG.011 spp. & 0.04673 & \\
\hline Lachnoclostridium spp. & 0.00029 & \\
\hline $\begin{array}{l}\text { Lachnospiraceae_NK4A136_group } \\
\text { spp. }\end{array}$ & 0.00637 & \\
\hline F.Peptococcaceae.UCS & $1.57 \mathrm{e}-06$ & 0.00019 \\
\hline Anaerotruncus spp. & 0.00799 & 0.02487 \\
\hline Harryflintia spp. & 0.02105 & \\
\hline Oscillibacter spp. & 0.01505 & \\
\hline Ruminococcaceae_UCG.010 spp. & 0.04265 & \\
\hline Ruminococcaceae_UCG.014 spp. & $8.72 \mathrm{e}-06$ & \\
\hline Ruminococcus spp. & $3.73 \mathrm{e}-06$ & 0.00302 \\
\hline F.Ruminococcaceae.UCS & 0.02286 & \\
\hline Allobaculum spp. & 0.00087 & 0.01719 \\
\hline Candidatus_Stoquefichus spp. & 0.04012 & \\
\hline Dubosiella spp. & 0.00068 & \\
\hline Faecalibaculum spp. & 0.03229 & \\
\hline Bilophila spp. & 0.00968 & \\
\hline F.Desulfovibrionaceae.UCS & $1.99 \mathrm{e}-07$ & \\
\hline Oxalobacter spp. & 0.01909 & \\
\hline Anaeroplasma spp. & 0.03002 & \\
\hline O.Mollicutes_RF39.UCS & 0.03361 & \\
\hline
\end{tabular}




\section{FIGURE LEGENDS}

657

658 Figure 1. Stratification of the samples. MDS plots based on Bray distance dissimilarity. A)

659 The samples are colored according to the Time and shaped according to Condition variable

660 B) The samples are colored according to the Enterotype variable calculated according to the

661 Bray-Curtis dissimilarity and shaped according to the Time variable.

662

663 Figure 2. Shannon alpha Diversity measure representation for the paired samples. A)

664 Shannon index according to the Time variable B) Shannon index according to the Condition

665 variable (C: Controls; HF: Heart Failure; SF: Sleep Fragmentation; HF+SF: Heart Failure

666 and Sleep Fragmentation. C) Variation of Shannon diversity indexes before and after the

667 experiment in each individual mouse. Samples are colored according to the experimental

668 condition.

669

670 Figure 3. Shannon index representation of the paired samples according to the Condition

671 variable. The line inside the boxplot represents the median for each of the groups. A)

672 Considering only post samples B) Considering both pre and post samples. Kruskal-Wallis

673 test showed significance $(\mathrm{P}=0.028)$.

674

675 Figure 4. Heatmap representing the 32 significantly differentially abundant taxa at the

676 species level between groups in post samples. The logarithm of only the significant p-

677 values are reported $(\mathrm{P}<0.05)$, where the infinite values are represented as $2.2 \mathrm{e}-16$. The

678 sign of the values was transformed to positive or negative according to the direction of the

679 alteration: positive values for increases in the first group within the comparison and 
bioRxiv preprint doi: https://doi.org/10.1101/2020.09.11.294447; this version posted September 15,2020 . The copyright holder for this preprint (which was not certified by peer review) is the author/funder, who has granted bioRxiv a license to display the preprint in perpetuity. It is made available under aCC-BY-NC 4.0 International license.

680 negative values for the decreases. Example: A value of 7.218 for Bacteroides acidifaciens

681 when comparing $\mathrm{C}$ to $\mathrm{HF}$ means that this species is significantly higher in $\mathrm{C}$ compared to

682 HF.

683

684 
bioRxiv preprint doi: https://doi.org/10.1101/2020.09.11.294447; this version posted September 15, 2020. The copyright holder for this preprint (which was not certified by peer review) is the author/funder, who has granted bioRxiv a license to display the preprint in perpetuity. It is made available under aCC-BY-NC 4.0 International license.

\section{Figure 1.}

686 A

687

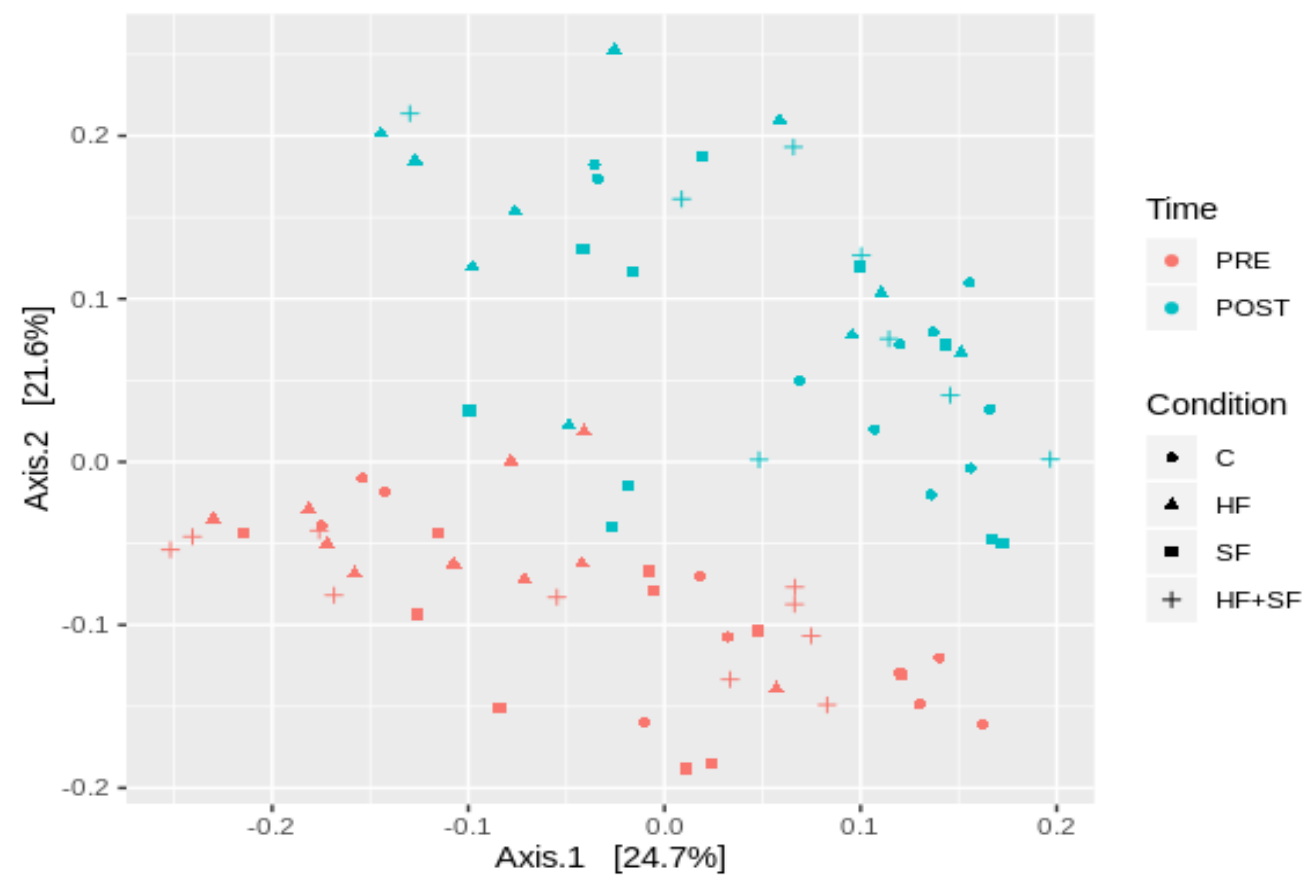

688 B

689

690

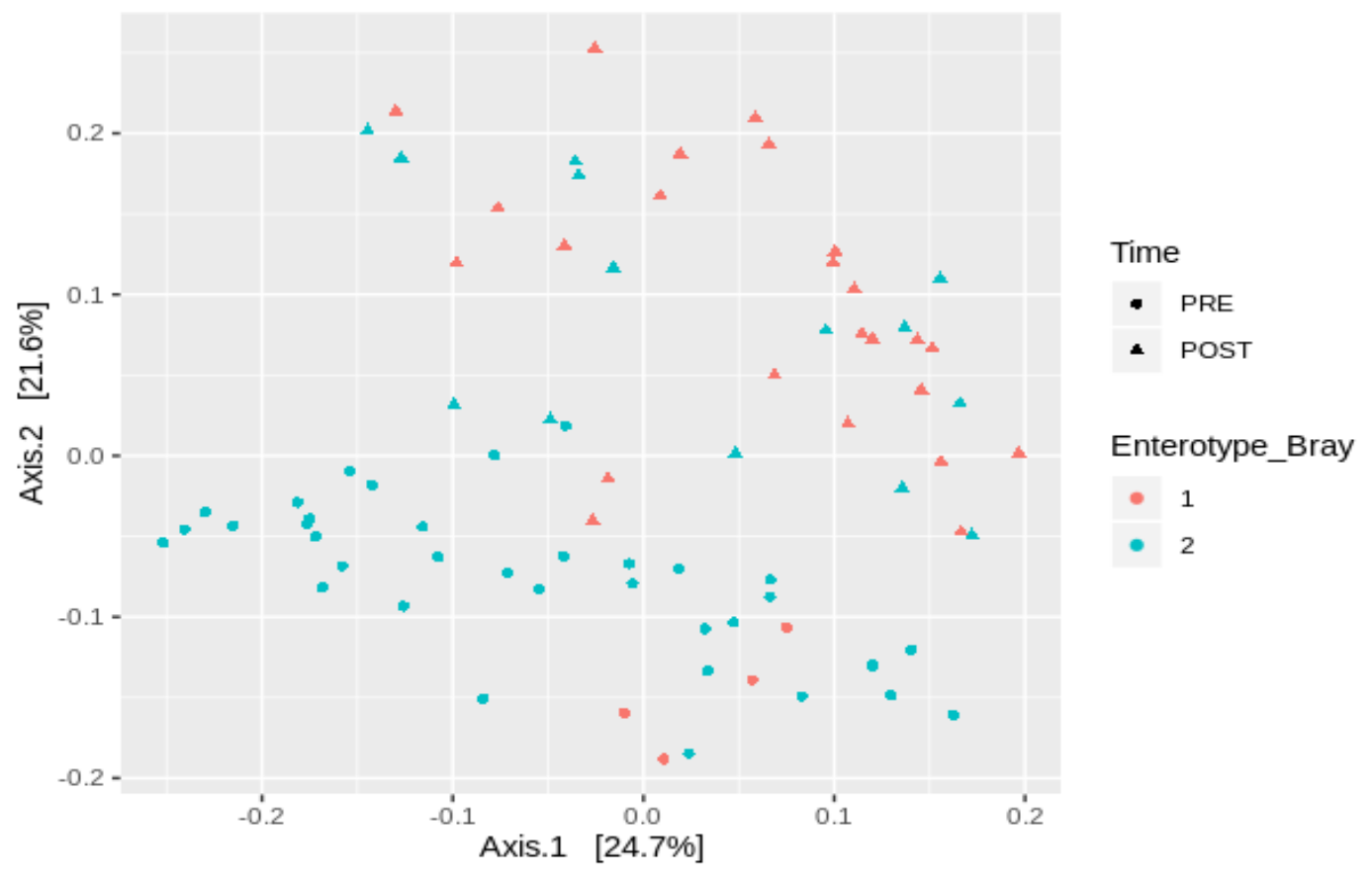


bioRxiv preprint doi: https://doi.org/10.1101/2020.09.11.294447; this version posted September 15, 2020. The copyright holder for this preprint (which was not certified by peer review) is the author/funder, who has granted bioRxiv a license to display the preprint in perpetuity. It is made available under aCC-BY-NC 4.0 International license.

\section{Figure 2}

692 A

693

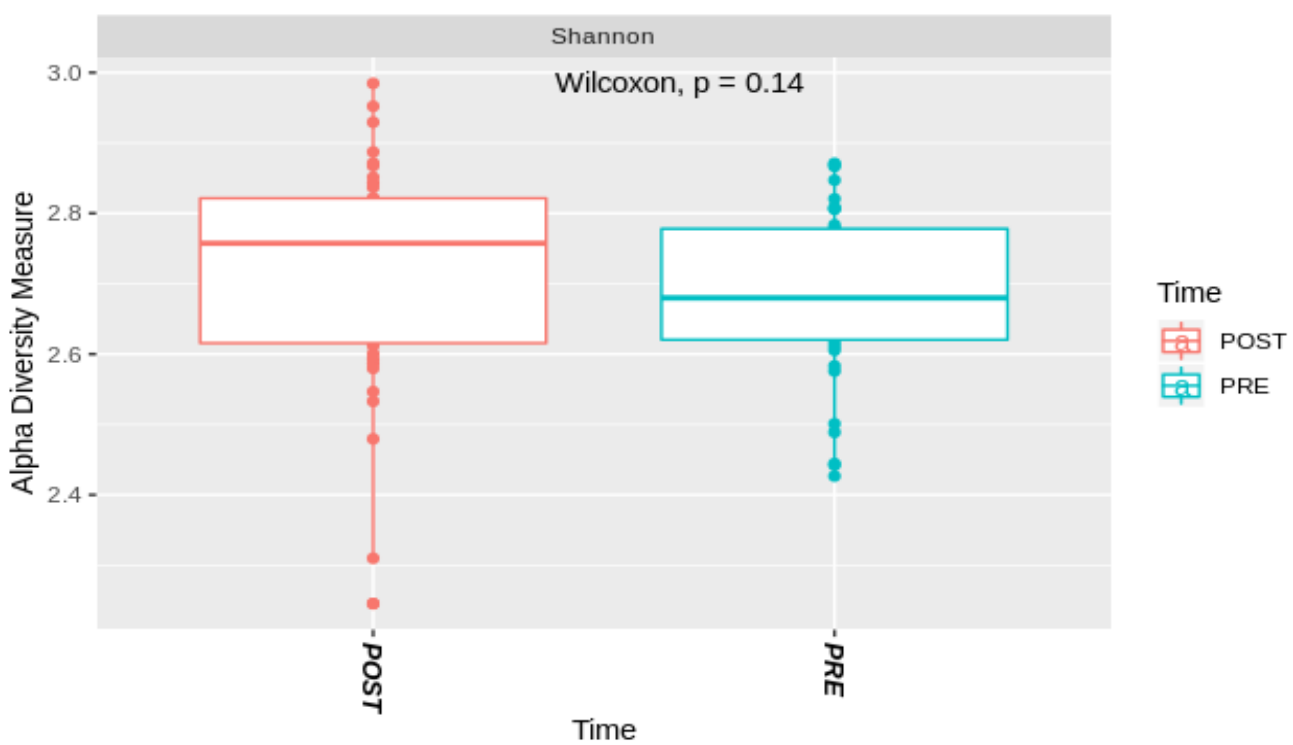

694 B

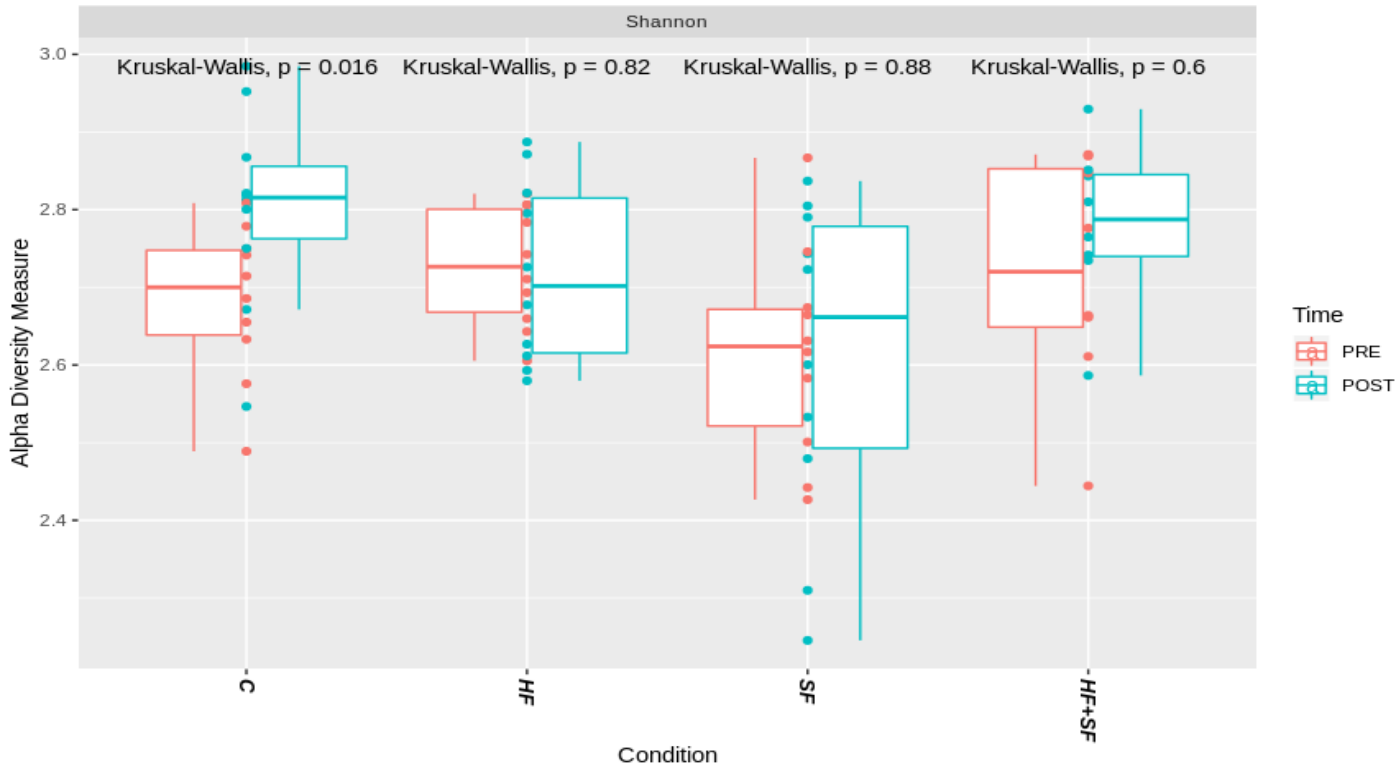

695

C 
bioRxiv preprint doi: https://doi.org/10.1101/2020.09.11.294447; this version posted September 15,2020 . The copyright holder for this preprint (which was not certified by peer review) is the author/funder, who has granted bioRxiv a license to display the preprint in perpetuity. It is made available under aCC-BY-NC 4.0 International license.

697

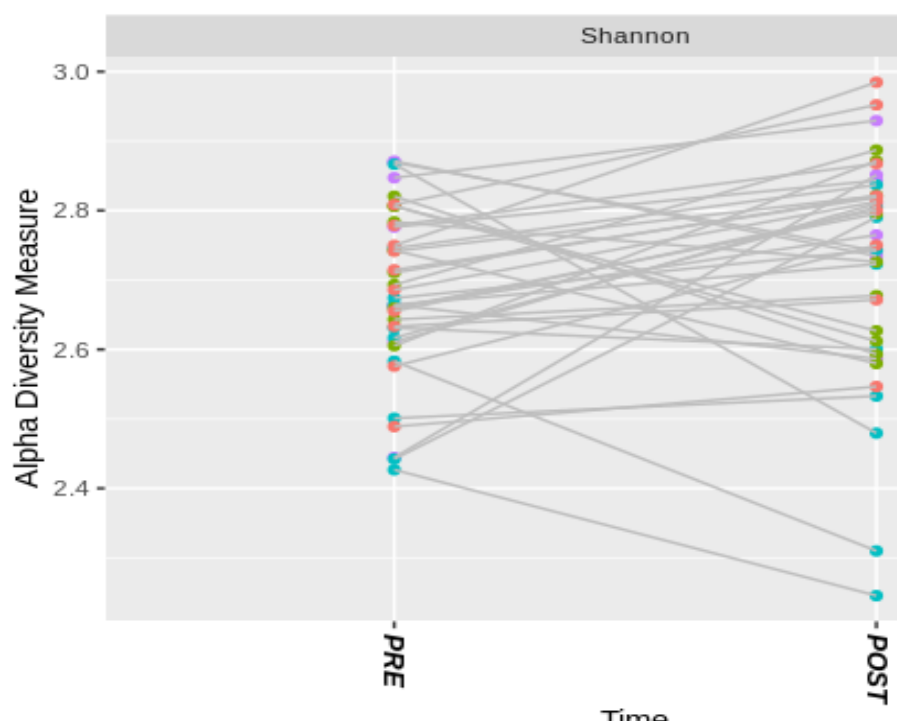

Time

698 
bioRxiv preprint doi: https://doi.org/10.1101/2020.09.11.294447; this version posted September 15, 2020. The copyright holder for this preprint (which was not certified by peer review) is the author/funder, who has granted bioRxiv a license to display the preprint in perpetuity. It is made available under aCC-BY-NC 4.0 International license.

699 Figure 3

$700 \quad \mathbf{A}$

701

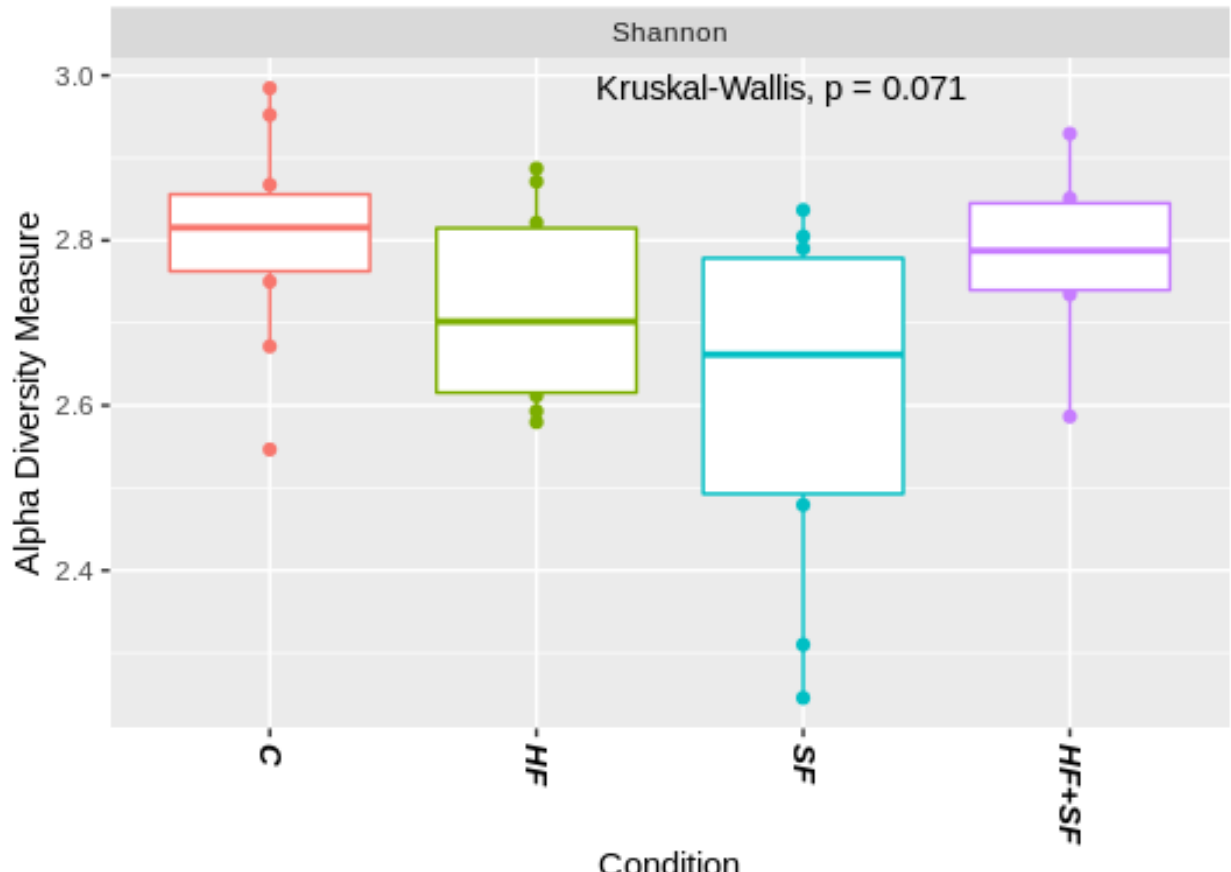

Condition

安 C

亩 $\mathrm{HF}$

国 SF

(1) HF+SF

\section{B}

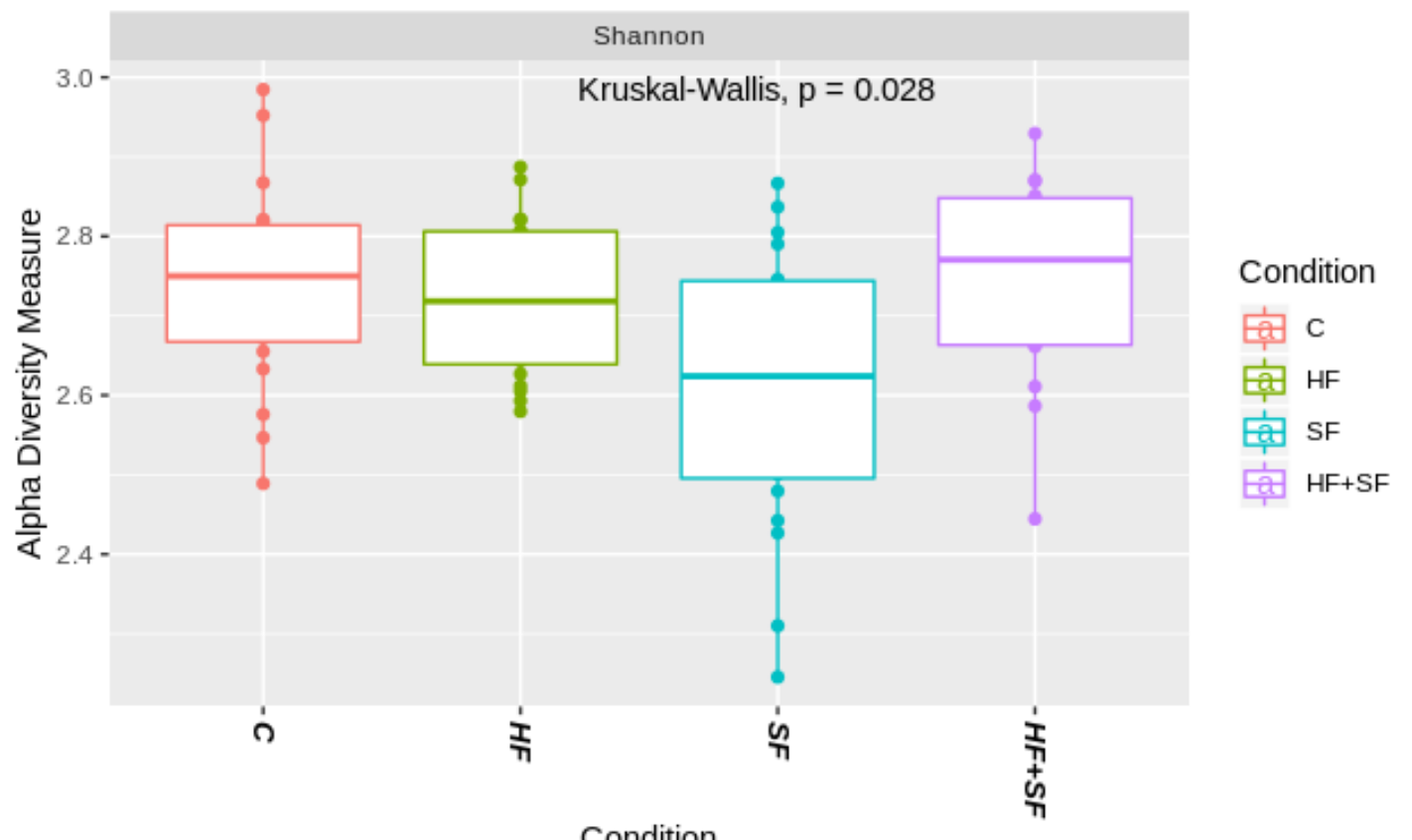


bioRxiv preprint doi: https://doi.org/10.1101/2020.09.11.294447; this version posted September 15, 2020. The copyright holder for this preprint (which was not certified by peer review) is the author/funder, who has granted bioRxiv a license to display the preprint in perpetuity. It is made available under aCC-BY-NC 4.0 International license.

\section{Figure 4}

705

706

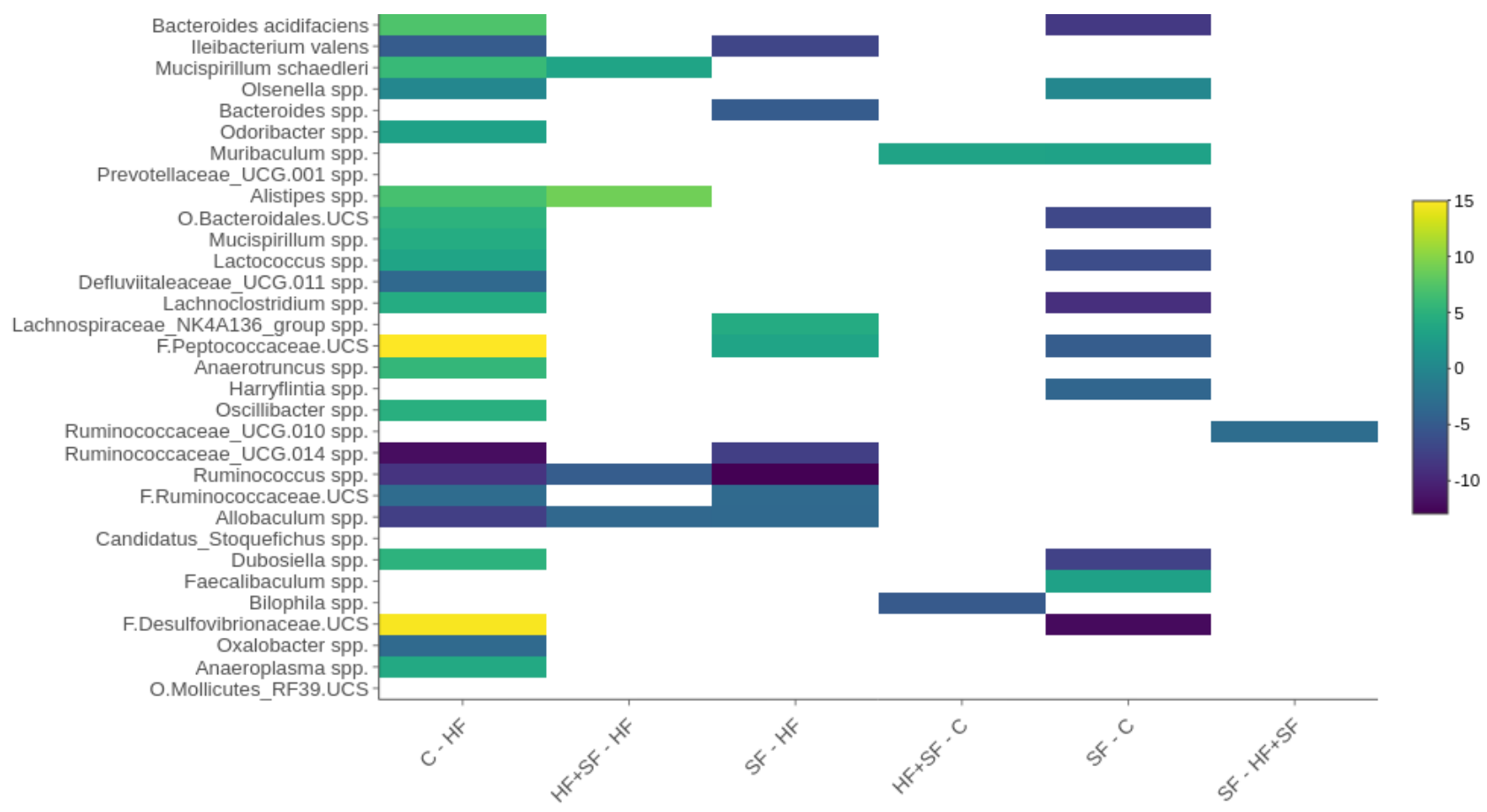

